\title{
Which psychological factors change when habitual water treatment practices alter?
}

\author{
Hans-Joachim Mosler • Silvie Kraemer
}

Received: 17 March 2011 / Accepted: 7 June 2011 /Published online: 23 June 2011

(C) Springer-Verlag 2011

\begin{abstract}
Aim Household water treatment systems (HWTS) and safe storage systems are an effective measure to ensure safe water supply. The adoption of HWTS requires long-term changes in behavior. During campaigns for health related behavior change, many people appear to have fixed behavioral patterns that are difficult to change. Since behavior change originates in the altering of inner psychological factors, it is necessary to investigate the transformation of these factors. Five categories of psychological factors are identified as responsible for the formation of habitual behavior: risk beliefs, attitudinal beliefs, normative beliefs, ability beliefs, and maintenance beliefs. This study analyzes which factors change when long-term users of HWTS, non-users, or 'tryers' (using HWTS occasionally), transform their behavior type or remain in their current behavior type.

Subjects and methods Data were obtained by conducting six panel interviews about the use of solar water disinfection (SODIS) over a period of 14 months, with 694 households, in the slum areas of Harare, Zimbabwe.

Results The results reveal that progressing to a higher level of user type (one who increases their use of SODIS), or staying at a high level of use (maintaining their level of use) is associated with the user's ability to avoid being hindered by other habits, to remember the behavior in respective situations, and to notice that other people are also using SODIS.

Conclusion Suggested strategies which may foster these factors include the control of distracting stimuli, forming
\end{abstract}

H.-J. Mosler $(\bowtie) \cdot$ S. Kraemer

Department of System Analysis,

Eawag, Swiss Federal Institute of Aquatic Science and Technology,

Überlandstrasse 133, P.O. Box 611, 8600 Duebendorf, Switzerland

e-mail: mosler@eawag.ch implementation intentions, daily routine planning, applying reminders, and using public commitments.

Keywords Household water treatment . Adoption.

Behavior change $\cdot$ Habits

\section{Introduction}

Nearly 900 million people collect drinking water from unimproved sources such as rivers, ponds, and shallow open wells. Nearly half of the world's population faces water scarcity, while water quality and quantity problems are increasing (WHO/UNICEF 2010). Each year 1.8 million children die before their fifth birthday due to diarrhea, nearly all of them in developing countries. The World Health Organization (WHO) estimates that safe water supply, sanitation, and hygiene could prevent $88 \%$ of these deaths (2007). To combat this preventable global burden, the promotion of household water treatment systems (HWTS) and safe storage systems represents an effective, realistic, and cost-effective method to accelerate health gains for those without reliable access to safe drinking water (WHO 2007).

Adoption of HWTS systems is a process of behavior change where long-term campaigns are often needed. During a long-term campaign for health behavior change, one has to address the problem that many people appear to have fixed behavioral patterns. Some people never change, while others change but fall back into old habits and some stick to the new (desirable) behavior. Even when people have adopted the new behavior for a longer period, they may relapse and fall back into their old habits. Since behavior is the outcome of inner psychological factors, some of these factors must change in order for people to 
alter their behavior. To gain insight into how households can be successfully encouraged to adopt water treatment techniques in the long-term, it is of particular interest to understand the individual psychological factors related to water consumption. The assessment of factors based on psychological theories of human behavior have provided essential inputs for the accurate design of promotion campaigns (e.g. Altherr et al. 2008; Heri and Mosler 2008; Moser and Mosler 2008). However, to our knowledge, there has been no research lasting longer than 1 year on changing inner psychological factors and the long-term adoption of HWTS.

With the present study, we intend to close this research gap and investigate the following question: Which internal factors change when fixed long-term behavior types transform into the intended behavior, or relapse to the non-intended behavior? The factors examined in this study originate in psychological theories about health-related behavior, planned behavior, and habit development, which have all shown their ability to explain health-related behaviors (see Bartholomew et al. 2006). In the following section, we elaborate on these factors as they relate to their respective psychological theories.

The goal of each behavior-change campaign is to build a long-term habitual behavior amongst the majority of the target population, which is demonstrated when the population assumes the behavior nearly automatically without any cognitive effort, but with intention. Common psychological theories identify five blocks of factors that are responsible for the formation of habitual behavior: risk beliefs, attitudinal beliefs, normative beliefs, ability beliefs, and maintenance beliefs. Risk beliefs are postulated by the Health Belief Model (Becker 1974), the Protection Motivation Theory (Prentice-Dunn and Rogers 1986), and by the Health Action Process Approach (Schwarzer 2008). The Theory of Planned Behavior (Ajzen 1991) identifies attitudinal, normative, and ability beliefs and was successfully applied in explaining different health behaviors such as condom use (e.g., Albarracin et al. 2001; Sheeran and Taylor 1999), leisure (e.g., Ajzen and Driver 1992), exercise (e.g., Nguyen et al. 1997), and diet behavior (e.g., Conner et al. 2003). In this study, we add maintenance beliefsbeliefs about how to put a behavior into practice - to this theory (Gollwitzer and Sheeran 2006) because such beliefs are responsible for the maintenance of behavior (as postulated in the Transtheoretical Model of Change; Prochaska and DiClemente 1983).

When addressing risk beliefs, we differentiate between perceived vulnerability and perceived severity. Perceived vulnerability refers to a person's subjective perception of his or her risk of contracting a particular condition or illness. Perceived severity is a person's perception of the seriousness of the consequences of contracting a particular condition or illness (Floyd et al. 2000; Brewer et al. 2007). In terms of attitudinal beliefs, we consider instrumental beliefs such as those evaluating the costs and benefits of the new behavior or the amount of time needed to perform it. Taking into account that attitudes have an additional affective component (Trafimow and Sheeran 1998; Mosler et al. 2008), we also consider affective attitudes, which are feelings that arise when performing or thinking about the behavior. Since the formation of positive attitudinal beliefs is the result of induced persuasion processes, as described in the Elaboration Likelihood Model (Petty and Cacioppo 1986; Mosler et al. 2001), we take into account the persuasiveness of the campaign agents (e.g., the credibility and kindness of the promoters). When addressing normative influences, two kinds of beliefs are relevant: first, the descriptive norm expresses perceptions about which behaviors are typically performed, and second, the injunctive norm expresses perceptions about which behaviors are typically approved or disapproved (Cialdini 2003; Schultz et al. 2007). Additionally, we consider the frequency of communicating about SODIS as an indicator of how much social influence a topic exerts in a social system. In the fourth factor block - ability beliefs-we consider responseefficacy, which is the perceived likelihood that performing the behavior will produce a given outcome, also known as outcome expectation (Ajzen 2002; Lam 2006). Finally, in the fifth factor block - maintenance beliefs-action control is regarded as the personal management of conflicting goals and distracting cues when it is intended to maintain a behavior (Gollwitzer 1999). To preserve the behavior as a habit, the person must also develop the ability to remember the intended behavior (Verplanken and Orbell 2003).

Several publications reveal that the aforementioned factors are relevant for the prediction of safe water use. Altherr et al. (2008) successfully explain the consumption of solar disinfected drinking water in Nicaragua based on the Theory of Planned Behavior (Ajzen 1991). Meanwhile, Heri and Mosler (2008) show that attitudinal components such as costs and taste, as well as the injunctive norm, have significant influences on the water consumption of solar disinfected drinking in Bolivia. The result on the injunctive norm was corroborated by a study by Graf et al. (2008) on two behaviors, as well as on solar water disinfection and for hygiene behavior in the Kibera slum in Nairobi (Kenya) and by the study of Kraemer and Mosler (2010) on the intention to use solar water disinfection in the slums of Harare (Zimbabwe). Therefore, it can be concluded that approaching use factors from the perspective of health behavior theories in developed countries is a successful means of predicting the consumption of healthy disinfected drinking water by populations in developing countries. However, most of these findings are limited to describing short-term behavior changes, but for a campaign to be 
successful, long-term changes that result in the habitual use of HWTS are necessary. In this study, we explore how changes in psychological factors are responsible for behavioral changes in long-term adopters or long-term non-adopters of HWTS.

In this research project, we analyze the change in the above factors with regard to the adoption of solar water disinfection (SODIS) in Zimbabwe. We characterize different behavior types by dividing the period of a behavior change campaign for the dissemination of SODIS into two periods: one period of 5 months and one period of 9 months. Those persons who continuously refrained from using SODIS in the first period were named 'long-term nonusers,' the persons using SODIS occasionally were labeled 'long-term tryers,' and those persons constantly performing the behavior of using SODIS were referred to as 'long-term users.' We endeavored to find out whether these user types changed between the first and the second period and which factors influenced these changes. Our exploration of the changes in factors led to the following research questions:

1. Change of long-term users: (1) Do any factors change when long-term users continue to be users? (2) Which factors have changed when long-term users fall back to being tryers? (3) Which factors change when long-term users relapse into being non-users?

2. Change of long-term tryers: (1) Do any factors change when long-term tryers continue to be tryers? (2) Which factors change when long-term tryers develop into users? (3) Which factors have changed when long-term tryers relapse into being non-users?

3. Change of long-term non-users: (1) Do any factors have changed when long-term non-users users continue to be non-users? (2) Which factors have changed when long-term non-users develop into tryers? (3) Which factors have changed when long-term non-users develop into users?

Knowledge about these changing factors is necessary for developing strategies of behavior change to transform non, or irregular users of HWTS, into regular, habitual users and to keep users as long-term users.

\section{Methods}

Research area and sample

The field research for this study was carried out in informal settlements in high-density areas around Harare, Zimbabwe. At the beginning of this longitudinal survey, the participants in this field research were $N=878$ inhabitants of high-density areas, $N=364$ from Hopley Farm (overall inhabitants about 50,000 ), southwest of Harare, and $N=514$ from Epworth (overall inhabitants about 350,000), southeast of Harare. The interviewees were $91 \%$ women and $9 \%$ men. The mean age was $M=34$; the mean number of years of education were $M=8$ years, and the mean income was $M=\$ 400,000$ Zim (about \$15 USD at the time of research) per month per household (with $M=4.5$ persons per household). This means that, on average, people in the research areas live far below the poverty line of $\$ 1$ USD per day. On average, each household has one child $(M=0.9)$ below 5 years of age.

Procedure

Data were obtained by conducting structured interviews in the households of the interviewees. Voluntary participants were chosen randomly by means of random route sampling (Hoffmeyer-Zlotnik 2003). This means the interviewers visited every third household in their assigned area. The duration of this study lasted from December 2007 to January 2009. The first period occurred between December 2007 and April 2008 where a panel was conducted every 3 months. Thus, panel 1, panel 2, and panel 3 took place in the first period, while the second period, from July 2008 to January 2009, comprising panels 4, 5, and 6, was conducted between equal time distances. To disseminate SODIS use and increase user numbers, behavior-change interventions were applied during the whole campaign. The different interventions were chosen on behalf of certain indicators-e.g. how well known SODIS was, or whether people had enough background knowledge about health and water treatment. The details of the chosen interventions are beyond the scope of this paper, since the focus of this paper is on how psychological factors change during longterm behavior change. Details about the interventions can be found in Kraemer and Mosler (2011).

Questionnaire and variables

Various questions from the questionnaire were put together to form the psychological factors that were examined in this study. User types were assessed with a single question, but then calculated over time. In the following section, we first present the user-type calculations, followed by examples of the wording of the questions for each factor. The reliability measure (Cronbach's alpha) was calculated for each scale that was built for each period. All alphas were found to be sufficient regarding good values.

User types: Different kinds of users were classified according to the following question: "Are you doing SODIS?" This question has four possible self-statement answers: (1) I am doing SODIS regularly, (2) I am doing SODIS sometimes or irregularly, (3) I have tried SODIS but stopped, and (4) I am not doing SODIS. This question was 
asked during each of the six panel surveys, and an aggregate measure of usage type was formed from the first three and the last three panels. Interview points were divided into two phases with three time points each: from panel 1 to panel 3 (T1-3) and from panel 4 to panel 6 (T4$6)$. We differentiate between users (people who state that they are (1) regular users or (2) irregular users at three points in time), non-users (people who state that they are (3) not using SODIS at three points in time) and tryers (everything in between: people who do SODIS and then stop, who start later, who stop and then start again). Consequently, if people self-classified themselves in the same way, in the three panels for each period, they could be assigned to the according group (users or non-users), and if they classified differently within one period, they were labeled tryers. From $N=878$ people who participated in the interviews, only those who answered the interviews at all three points of time from T1 to T3 or from T4 to T6 could be included in the study. User group numbers and their changes between periods are in Table 1 in the results section.

The main measurements are outlined in the following:

- Vulnerability was measured using five items-e.g. "Do you think that drinking raw water makes you healthier or less healthy?"

- Severity was measured using five items, one of which was "How serious is it when you or your kids have diarrhea?"

- Evaluative beliefs were measured with two questions that considered how people value SODIS using questions such as, "Is it worth it to do SODIS?"

- Persuasiveness measured six perceived attributes of the promoters-e.g. "Did that person know what he/she was talking about?"
- Descriptive norm was recorded with two items, one of which was "How many people do you know in your village who do SODIS?"

- Injunctive norm consisted of three items. One example is "How would or do other people think about you when you do SODIS?

- Talking frequency is recorded with two questions, for example: "How often do you talk about SODIS or water treatment?"

- Response efficacy was coded with two questions-e.g. "Do you think drinking SODIS water can make you healthier or less healthy?"

- Action control was measured with four items, for example: "Do other habits hinder you in doing SODIS?"

- Remembering consisted of four items, one of which was "How easy is it for you to remember to do SODIS?"

All of the answers were standardized to range from zero to 1 or from -1 to +1 (in the case of bipolar variables). The answer that indicates favorable behavior is 1 , and the answer that is most unfavorable to the desired behavior is 0 or -1 . The bipolar variables have nine-point-scale answer categories, and the unipolar variables have five-point-scales.

\section{Statistical analysis}

In this study we will compare the means in factors over different time periods. Therefore we use the General Linear Model (GLM) for repeated measures. This method reveals whether the means between groups are different, changed over time, and changed differently over time. General Linear Models (GLMs) were calculated for each factor to see whether the groups differ (e.g. group $\mathrm{A}=$ non-users at
Table 1 Means of variables for user types non-user to non-user or tryer; the $F$-values from the GLMs for group and time differences and time by group $(\mathrm{t} * \mathrm{~g})$. Time period $1=\mathrm{T} 1-3$, time period 2=T4-6. Significance levels are indicated the following: $* * *=p<.000, * *=p<.005$, $n s=p>.005$

\begin{tabular}{|c|c|c|c|c|c|c|c|c|c|}
\hline \multirow[b]{2}{*}{ Time period } & \multicolumn{3}{|c|}{ Non-user to non-user } & \multicolumn{3}{|c|}{ Non-user to tryer } & \multicolumn{3}{|c|}{ GLM: $F$-value } \\
\hline & 1 & 2 & $2-1$ & 1 & 2 & $2-1$ & Group & Time & $\mathrm{t}^{*} \mathrm{~g}$ \\
\hline \multicolumn{10}{|l|}{ Factor } \\
\hline Vulnerability & .62 & .52 & -.10 & .64 & .61 & -.03 & $16.17 * * *$ & $18.93 * * *$ & $5.78 \mathrm{~ns}$ \\
\hline Severity & .45 & .36 & -.09 & .44 & .40 & -.04 & $2.75 \mathrm{~ns}$ & $42.14 * * *$ & $5.11 \mathrm{~ns}$ \\
\hline Evaluation beliefs & .83 & .95 & .12 & .87 & .87 & .00 & $1.42 \mathrm{~ns}$ & $6.50 \mathrm{~ns}$ & $6.42 \mathrm{~ns}$ \\
\hline Affective beliefs & .64 & .42 & -.21 & .64 & .61 & -.03 & $19.18^{* * *}$ & $39.27 * * *$ & $24.80 * * *$ \\
\hline Descriptive norm & .47 & .34 & -.13 & .53 & .46 & -.07 & $34.89 * * *$ & $62.53 * * *$ & $6.75 \mathrm{~ns}$ \\
\hline Injunctive norm & .69 & .43 & -.26 & .67 & .40 & -.26 & $1.50 \mathrm{~ns}$ & $168.96^{* * *}$ & $.01 \mathrm{~ns}$ \\
\hline Response efficacy & .67 & .44 & -.23 & .65 & .59 & -.06 & $4.78 \mathrm{~ns}$ & $67.33 * * *$ & $23.40 * * *$ \\
\hline Action control & .56 & .44 & -.12 & .62 & .66 & .04 & $15.34 * * *$ & $8.78 * *$ & $36.84 * * *$ \\
\hline Remembering & .02 & .00 & -.02 & .02 & .15 & .13 & $9.22 * *$ & $8.85^{* *}$ & $13.75^{* * *}$ \\
\hline Persuasiveness & .69 & .61 & -.08 & .71 & .71 & -.00 & $21.41 * * *$ & $10.69 * *$ & $9.37 * *$ \\
\hline Talking frequency & .49 & .37 & -.12 & .56 & .59 & .03 & $33.32 * * *$ & $7.73 * *$ & $20.96 * * *$ \\
\hline
\end{tabular}


T1-3 stay non-users at $\mathrm{T} 4-6$; group $\mathrm{B}=$ non-users at $\mathrm{T} 1-3$ develop into tryers at T4-6), whether there is a significant development over time (from T1-3 to T4-6; t), and, most importantly, whether the development over time differs between groups (interaction effect; $\mathrm{t}^{*} \mathrm{~g}$ ). $F$-values are indicated for these results. Significance levels were adjusted due to multiple testing (with 11 factors; mathematical formula can be found in Cohen 1988) to $p<0.005$. Such GLMs show whether the development between the periods is different depending on the user-type development that takes place. In other words, $F$-levels indicate whether someone who develops, for example, from a non-user into a tryer, shows different increases or decreases in factors than someone who stays a non-user. Therefore, if the $F$ value for the group development is significant, then there is a difference between the groups (non-user/non-user and non-user/tryer). Significant values for time development indicate that the factor in period 1 has a significantly different value at period 2; thus, there is a change taking place over time. The most important indicator for essential developments is the interaction effect between $t^{*} \mathrm{~g}$. If time by group developments are significant, it means that the groups (e.g., whether people stay non-users or develop into tryers from being non-users at period 1) are developing differently over time in the respective factor.

\section{Results}

The guiding question for the following calculations was which of the eleven aforementioned factors change when long-term user types (non-users, tryers, or users over a period of 3 panel interviews) develop into other types of users, or whether any factors change when user types stay the same. We will address this question by first listing the means for each factor for both periods of time (T1-3 and T4-6) for each user type transformation. Occurrences of user type transformations were from non-user to non-user, or tryer (no non-users changed into users); from tryers to non-users, tryers, or users; and from users to tryers, or users (no users relapsed into non-users). As previously mentioned, only those who answered the interviews during all three periods were eligible for inclusion in the study, therefore, $N=694$ are included in the analysis. Figure 1 below displays these numbers and the changes that occurred between groups.

In the following sections, the means for each factor at both periods are displayed. Table 1 shows the results of the change from non-user to non-user, or tryer; Table 2 shows the transitions from tryer to non-user, tryer, or user; and Table 3 shows the transition from user to tryer, or user. After each table, we will explain only those changes that have a significant time by group interaction effect.

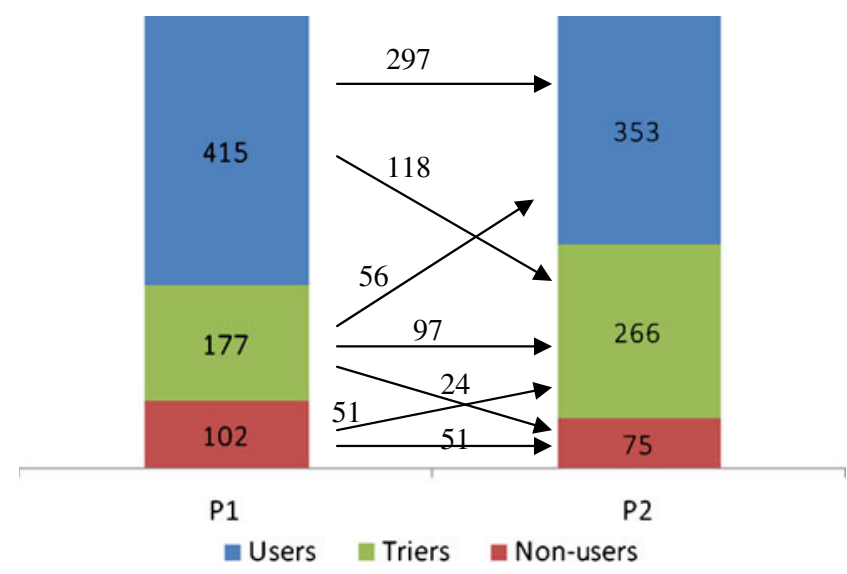

Fig. 1 User types and their transition over periods of time. The labeled arrows indicate the number of persons who changed from one user category to another from time period P1-P2

The magnitude of most (but not all) factors decreased among all non-users who did not change groups. Among those who moved up to being a tryer, this decrease was less pronounced for most factors, and in some cases was converted into an increase. The affective beliefs, response efficacy, and persuasiveness factors have a greater decrease for those who stay as non-users, instead of developing into tryers. The action control, remembering, and talk frequency factors increase, rather than decrease significantly, for those who move up to being a tryer from a non-user, instead of staying a non-user.

Table 2 shows that severity decreases significantly during the transition from tryer to tryer instead of from tryer back to non-user. This means that those who stay tryers, instead of relapsing into non-users, are experiencing a more pronounced decrease in severity. The descriptive norm, action control, and remembering factors decrease significantly during the transition from tryer to non-user, rather than from tryers to remaining tryers. This means that people who remain tryers show a less pronounced decrease in these factors.

Severity decreases significantly for those who develop from tryer to user as opposed to those who remain tryers. The descriptive norm, action control, and remembering factors increase significantly during the development from tryer to user, rather than for those who remain tryers.

For long-term users, the vulnerability, severity, injunctive norm, and talk frequency factors decrease more for those who relapse from users to tryers instead of remaining users (see Table 3). The descriptive norm, action control, remembering, and persuasiveness factors increase significantly for those who stay users in comparison with those who relapse into tryers. However, the development of the descriptive norm factor over time is not significant although, group and time by group changes are significant. 
Table 2 Means of variables for user types tryer to non-user, tryer, or user; $F$-values from the GLMs for group and time differences and time by group $\left(\mathrm{t}^{*} \mathrm{~g}\right)$. Time period $1=\mathrm{T} 1-3$, time period $2=\mathrm{T} 4-6$. Significance levels are indicated the following: $* * *=p<.000, * *=p<.005, n s=p>.005$

\begin{tabular}{|c|c|c|c|c|c|c|c|c|c|c|c|c|}
\hline \multirow[b]{2}{*}{ Time period } & \multicolumn{3}{|c|}{ Tryer to non-user } & \multicolumn{3}{|c|}{ Tryer to tryer } & \multicolumn{3}{|c|}{ Tryer to user } & \multicolumn{3}{|c|}{ GLM: $F$-value } \\
\hline & 1 & 2 & $2-1$ & 1 & 2 & $2-1$ & 1 & 2 & $2-1$ & Group & Time & $\mathrm{t}^{*} \mathrm{~g}$ \\
\hline \multicolumn{13}{|l|}{ Factor } \\
\hline Vulnerability & .70 & .58 & -.12 & .74 & .63 & -.11 & .79 & .74 & -.06 & $19.36^{* * *}$ & $87.19 * * *$ & $4.76 \mathrm{~ns}$ \\
\hline Severity & .49 & .40 & -.09 & .57 & .45 & -.12 & .70 & .50 & -.20 & $23.39 * * *$ & $130.99 * * *$ & $7.85 * *$ \\
\hline Evaluation beliefs & .85 & .93 & .08 & .90 & .83 & -.07 & .88 & .95 & .07 & $7.42 \mathrm{~ns}$ & $3.39 \mathrm{~ns}$ & $19.03 \mathrm{~ns}$ \\
\hline Affective beliefs & .74 & .47 & -.27 & .82 & .64 & -.19 & .88 & .65 & -.23 & $9.79 * * *$ & $76.69 * * *$ & $.93 \mathrm{~ns}$ \\
\hline Descriptive norm & .53 & .40 & -.13 & .66 & .61 & -.05 & .69 & .82 & .13 & $40.79 * * *$ & $.90 \mathrm{~ns}$ & $18.31 * * *$ \\
\hline Injunctive norm & .69 & .41 & -.29 & .79 & .50 & -.29 & .85 & .67 & -.18 & $17.57 * * *$ & $120.47 * * *$ & $3.21 \mathrm{~ns}$ \\
\hline Response efficacy & .69 & .52 & -.18 & .80 & .66 & -.14 & .88 & .70 & -.18 & $8.11 * * *$ & $72.44 * * *$ & $.53 \mathrm{~ns}$ \\
\hline Action control & .70 & .51 & -.19 & .76 & .72 & -.04 & .74 & .80 & .06 & $8.43 * * *$ & $31.41 * * *$ & $41.79 * * *$ \\
\hline Remembering & .34 & .03 & -.32 & .59 & .41 & -.18 & .61 & .80 & .19 & $39.75 * * *$ & $10.49^{* *}$ & $25.98 * * *$ \\
\hline Persuasiveness & .76 & .65 & -.11 & .84 & .81 & -.04 & .93 & .92 & -.01 & $30.73 * * *$ & $9.92 * *$ & $2.34 \mathrm{~ns}$ \\
\hline Talking frequency & .61 & .38 & -.23 & .71 & .63 & -.07 & .76 & .70 & -.06 & $37.05 * * *$ & $38.13 * * *$ & $5.58 * *$ \\
\hline
\end{tabular}

In general, the tables show that all the factors decrease from the periods T1-3 to T4-6, except for the action control, remembering, and talk frequency factors for non-users who develop into tryers. Also increasing are the descriptive norm, action control, and remembering factors for tryers who develop into users. For users who stay users, the descriptive norm, action control, remembering, and persuasiveness factors rise. Overall, it is remarkable that the factors are displaying the most negative developments for non-users, intermediate ones for tryers, and the most positive ones for users.

\section{Discussion}

In Fig. 2 the main results are summarized and displayed in a comprehensive form. With regard to the research questions, the following answers can be interpreted: when long-term users commenced being users - research question 1(1) - they recognized more people doing SODIS; they were less hindered by concurrent habits; they were better able to remember when to do SODIS; the promoters of the campaign were perceived as more persuasive. When long-term users fell back to being tryers - research question 1(2) - they felt less vulnerable; they estimated less negative impact of diarrhea; they were more aware that others disapproved of doing SODIS; they were talking less about SODIS. We did not find a single case where long-term users relapsed into being nonusers - research question 1(3).

When long-term tryers improved to being usersresearch question 2(2) - they perceived more people doing SODIS; they were less hindered by concurrent habits; they were better able to remember when to do SODIS. Likewise,
Table 3 Means of variables for user types user to tryer or user; the F-values from the GLMs for group and time differences and time by group $(\mathrm{t} * \mathrm{~g})$. Time period $1=\mathrm{T} 1-3$, time period $2=$ T4-6. Significance levels are indicated the following: $* * *=\mathrm{p}<.000, * *=\mathrm{p}<.005$, $\mathrm{ns}=\mathrm{p}>.005$

\begin{tabular}{|c|c|c|c|c|c|c|c|c|c|}
\hline \multirow[b]{2}{*}{ Time period } & \multicolumn{3}{|c|}{ User to tryer } & \multicolumn{3}{|c|}{ User to user } & \multicolumn{3}{|c|}{ GLM: $F$-value } \\
\hline & 1 & 2 & $2-1$ & 1 & 2 & $2-1$ & Group & Time & $\mathrm{t} * \mathrm{~g}$ \\
\hline \multicolumn{10}{|l|}{ Factor } \\
\hline Vulnerability & .88 & .75 & -.12 & .91 & .89 & -.02 & $85.56 * * *$ & $227.14 * * *$ & $115.56 * * *$ \\
\hline Severity & .71 & .52 & -.18 & .73 & .67 & -.06 & $84.47 * * *$ & $234.01 * * *$ & $53.73 * * *$ \\
\hline Evaluation beliefs & .93 & .86 & -.06 & .96 & .95 & -.01 & $117.38 * * *$ & $56.53 \mathrm{~ns}$ & $40.61 \mathrm{~ns}$ \\
\hline Affective beliefs & .91 & .72 & -.20 & .92 & .72 & -.21 & $.02 \mathrm{~ns}$ & $192.78 * * *$ & $.11 \mathrm{~ns}$ \\
\hline Descriptive norm & .77 & .73 & -.04 & .82 & .86 & .04 & $89.68 * * *$ & $.06 \mathrm{~ns}$ & $20.46 * * *$ \\
\hline Injunctive norm & .91 & .68 & -.23 & .93 & .76 & -.17 & $12.75 * * *$ & $341.67 * * *$ & $8.25^{* *}$ \\
\hline Response efficacy & .94 & .77 & -.18 & .92 & .78 & -.14 & $.09 \mathrm{~ns}$ & $289.80 * * *$ & $3.88 \mathrm{~ns}$ \\
\hline Action control & .86 & .77 & -.09 & .88 & .91 & .02 & $69.54 * * *$ & $33.13 * * *$ & $88.32 * * *$ \\
\hline Remembering & .82 & .72 & -.10 & .86 & .92 & .06 & $80.16^{* * *}$ & $4.79 *$ & $101.78^{* * *}$ \\
\hline Persuasiveness & .89 & .89 & -.01 & .89 & .97 & .07 & $40.14 * * *$ & $28.14 * * *$ & $44.57 * * *$ \\
\hline Talking frequency & .84 & .66 & -.18 & .88 & .79 & -.09 & $79.47 * * *$ & $393.56 * * *$ & $39.77 * * *$ \\
\hline
\end{tabular}


Fig. 2 Factors changing when one user type is transforming into another type. "-" indicates that this factor is decreasing more for the regarded transformation than in comparison to other transformations. "+" indicates that this factor is increasing more for the regarded transformation than in comparison to other transformations

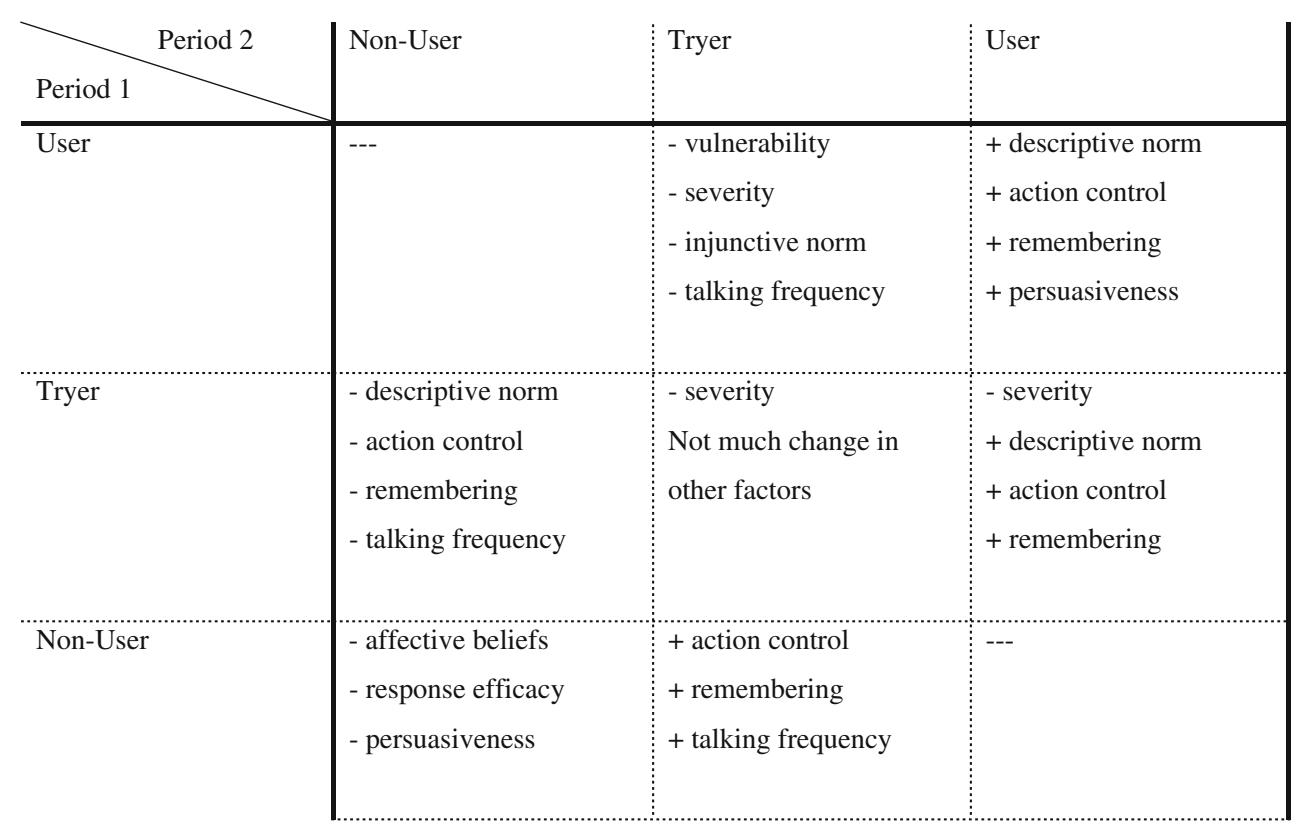

they estimated the impact of diarrhea as being less, which may be because the use of SODIS leads them to believe they are safe. When long-term tryers relapsed into being non-users, the aforementioned descriptive norm, action control, and remembering factors, as well as the frequency of talking decreased heavily - research question 2(3). When long-term tryers continued to be tryers - research question 2(1), then nearly all factors decreased but not to the extent as when tryers relapsed into being non-users. For tryers who remain tryers, severity decreases heavily; this may also be the result of participants believing that they are safe when using SODIS.

When long-term non-users remained non-users-research question 3(1) - they stated that they liked SODIS less; they were less convinced that SODIS can improve their health; furthermore, the campaign was not persuasive for them. When long-term non-users improved to being tryers - research question 3(2) - they were less hindered by alternative habits, they were better at remembering when to do SODIS, and they were talking more about SODIS. No long-term non-users moved up to being users - research question 3(3).

As a more general pattern, the results reveal that progressing to a higher user type who requires using SODIS more (i.e. from being a non-user to a tryer, or from a tryer to a user) and staying at a high level (e.g. users staying users) is associated with people managing not to be hindered by other habits, remembering the behavior in their respective situations, and noticing that other people are also doing SODIS. The last finding is consistent with the results of Mosler et al. (2010) who confirmed the importance for users of arsenic-free-deep tube wells to perceive that many others are also using such tube wells.
The possibilities for falling back into a lower user category are more diverse. Long-term tryers fall back when the reasons for improving are not obvious. Longterm users relapse when their risk perception lowers and they are thinking that others disapprove of doing SODIS. One common reason for falling back in both groups seems to be that the groups no longer talk as much about SODIS. Talking about a new behavior seems to serve as a social incentive and reminds the person to perform the behavior. Talking may also be self-persuasive (Aronson 1999) and has an impact on intention and behavior, as Kraemer and Mosler (2010) demonstrate. Long-term nonusers stay at their level because persuasive campaigns do not convince them to change their beliefs regarding SODIS, which is in line with the findings of Kraemer and Mosler (2010).

This study is unique in its design of the long-term observation of behavioral parameters over a period of nearly 1.5 years. The change from one long-term user type into another user type can be determined by the change in psychological factors. Additionally it would be beneficial to be able to show the impact of different campaign measures on the change in user type. This type of study was planned but failed to be executed because people were not able to recall what kind of campaign measures they had experienced. For example, when asked about receiving a reminder, they did not know whether they had received one even though we knew that this had been the case. To prevent misunderstandings in the future, the respective measures could be called into memory by showing pictures of them; this would enable participants to recall images of what the interviewer is asking. 


\section{Implications for campaigning practices}

In the following, specific behavior-change strategies will be developed as first proposals which would primarily have to be pretested in detail. Most decisive for the success of a behavior-change campaign seems to be that people acquire skills to improve action control and remembering, and that they get a better perception of other users of the technology (social influence). Action control means that a person has a strategy for how to perform the intended behavior even when conflicting goals and old habits arise and threaten to take over the guidance of the new behavior. Possible strategies could involve stimulus control by removing reminders or cues to engage in old behaviors and adding reminders or cues to engage in the new behavior (Bartholomew et al. 2006, pp 335-336). In addition, encouraging users to create implementation intentions would be useful by asking users to formulate when, where, and how to achieve his or her goals (Gollwitzer 1999; Tobias 2009), thus contributing to an automatic engagement in the new behavior. To increase automaticity, it may be useful to discuss a daily routine plan with the target group by discussing how this routine can be integrated into their lives so that it always takes place at the same time and during the same daily occurrences.

To foster remembering and prevent forgetting, prompts may be set by the person to trigger the behavior in the right situation. Self-commitments have the same effects: the person promises to execute the behavior either verbally or by signing a contract. If a visible sticker or poster shows the commitment to the public, then this also has an effect on the descriptive norm, as people perceive that others are performing the new behavior. Furthermore, it is possible to strengthen the descriptive norm by showing the new behavior more publicly, for example, by positioning the SODIS bottles in places that are more visible. In sum, the results of this research reveal that a convincing and understandable campaign for a behavior such as solar-water disinfection, should concentrate on actually helping people to implement the behavior they already intend to show.

Acknowledgements The presented research is part of a project entitled "Solar Disinfection of Drinking Water for Use in Developing Countries or in Emergency Situations: SODISWATER", Contract no: FP6-INCO-CT-2006-031650 from the European Union.

Conflicts of interest The authors state that they have no conflict of interest.

\section{References}

Ajzen I (1991) The theory of planned behavior. Organ Behav Hum Dec 50(2):179-211
Ajzen I (2002) Perceived behavior control, self-efficacy, locus of control, and theory of planned behavior. J Appl Soc Psychol 32 (4):665-683

Ajzen I, Driver BL (1992) Application of the theory of planned behavior to leisure choice. J Leisure Res 24(3):207-224

Albarracin D, Johnson BT, Fishbein M, Muellerieile PA (2001) Theories of reasoned action and planned behavior as models of condom use: meta-analysis. Psychol Bull 127(1):142-161

Altherr AM, Mosler HJ, Tobias R, Butera F (2008) Attitudinal and relational factors predicting the use of solar water disinfection: a field study in Nicaragua. Health Educ Behav 35(2):207-220

Aronson E (1999) The power of self-persuasion. Am Psychol 54 (11):875-884

Bartholomew LK, Parcel GS, Kok G, Gottlieb NH (eds) (2006) Planning health promotion programs: an intervention mapping approach. Jossey-Bass, San Francisco

Becker MH (1974) The health belief model and personal health behaviour. Slack, Thorofare, NJ

Brewer NT, Chapman GB, Gibbons FX, McCaul KD, Weinstein ND (2007) Meta-analysis of the relationship between risk perception and health behavior: the example of vaccination. Health Psychol 26(2):136-145

Cialdini RB (2003) Crafting normative messages to protect the environment. Curr Dir Psychol Sci 12(4):105-109

Cohen J (1988) Statistical power analysis for the behavioral sciences 2nd edn. Routledge, New York

Conner M, Kirk SFL, Cade JE, Barrett JH (2003) Environmental influences: factors influencing a woman's decision to use dietary supplements. J Nutr 133:1978-1982

Floyd DL, Prentice-Dunn S, Rogers RW (2000) A meta-analysis of research on Protection Motivation Theory. J Appl Soc Psychol 30:407-429

Gollwitzer PM (1999) Implementation intentions: strong effects of simple plans. Am Psychol 54:493-503

Gollwitzer PM, Sheeran P (2006) Implementation intentions and goal achievement: a meta-analysis of effects and processes. Adv Exp Soc Psychol 38:249-268

Graf J, Meierhofer R, Wegelin M, Mosler HJ (2008) Water disinfection and hygiene behaviour in an urban slum in Kenya: impact on childhood diarrhoea and influence of beliefs. Int J Environ Heal R 18(5):335-355

Heri S, Mosler HJ (2008) Factors affecting the diffusion of solar water disinfection: a field study in Bolivia. Health Educ Behav 35 (4):541-560

Hoffmeyer-Zlotnik JHP (2003) New sampling designs and the quality of data. Adv Method Stat 19:205-217

Kraemer SM, Mosler HJ (2010) Persuasion factors influencing the decision to use sustainable household water treatment. Int $\mathrm{J}$ Environ Heal R 20:61-79

Kraemer SM, Mosler HJ (2011) Factors from the Transtheoretical Model differentiating between solar water disinfection (SODIS) user groups. J Health Psychol 16(1):126-136

Lam SP (2006) Predicting intention to save water: theory of planned behavior, response efficacy, vulnerability and perceived effectiveness of alternative solutions. J Appl Soc Psychol 36 (11):2803-2824

Moser S, Mosler HJ (2008) Differences in influence patterns between groups predicting the adoption of a solar disinfection technology for drinking water in Bolivia. Soc Sci Med 67:497-504

Mosler HJ, Schwarz K, Ammann F, Gutscher H (2001) Computer simulation as a method of further developing a theory: simulating the Elaboration Likelihood Model (ELM). Pers Soc Psychol Rev 5(3):201-215

Mosler HJ, Tamas A, Tobias R, Caballero Rodriguez T, Guzman Miranda O (2008) Deriving interventions on the basis of factors 
influencing behavioral intentions for waste recycling, composting and reuse in Cuba. Environ Behav 40(4):522-544

Mosler HJ, Blöchliger OR, Inauen J (2010) Personal, social, and situational factors influencing the consumption of drinking water from arsenic-safe deep tubewells in Bangladesh. J Environ Manage 91:1316-1323

Nguyen MN, Potvin L, Otis J (1997) Regular exercise in 30- to 60year-old men: combining the Stages-Of-Change Model and the Theory of Planned Behavior to identify determinants for targeting heart health interventions. J Commun Health 22(4):233-246

Petty RE, Cacioppo JT (1986) The Elaboration Likelihood Model of Persuasion. In: Berkowitz L (ed) Advances in experimental social psychology. Academic, New York, pp 123-205

Prentice-Dunn S, Rogers RW (1986) Protection Motivation Theory and preventive health: beyond the Health Belief Model. Health Educ Res 1(3):153-161

Prochaska JO, DiClemente CC (1983) Stages and processes of selfchange of smoking: toward an integrative model of change. $\mathrm{J}$ Consult Clin Psych 51(3):390-395

Schultz PW, Nolan JM, Cialdini RB, Goldstein NJ, Griskevicius V (2007) The constructive, destructive, and reconstructive power of social norms. Psychol Sci 18(5):429-434
Schwarzer R (2008) Modeling health behavior change: how to predict and modify the adoption and maintenance of health behaviors. Appl Psychol Int Rev 57(1):1-29

Sheeran P, Taylor S (1999) Predicting intentions to use condoms: a meta-analysis and comparison of the theories of reasoned action and planned behavior. J Appl Soc Psychol 29:1624-1675

Tobias R (2009) Changing behavior by memory aids: a social psychological model of prospective memory and habit development tested with dynamic field data. Psychol Rev 116:408438

Trafimow D, Sheeran P (1998) Some tests of the distinction between cognitive and affective beliefs. Exp Soc Psychol 34(4):378-397

Verplanken B, Orbell S (2003) Reflections on past behavior: a selfreport index of habit strength. J Appl Soc Psychol 33(6):13131330

WHO (2007) Combating waterborne disease at the household level. http://www.who.int/water_sanitation_health/publications/ combating_diseasepartllowres.pdf. Cited 10 September 2010

WHO/Unicef (2010) Progress on sanitation and drinking water. 2010 Update. http://www.who.int/water_sanitation_health/ publications/9789241563956/en/index.html. Cited 10 September 2010 